\title{
Adjuvant Endocrine Therapy in Early Postmenopausal Breast Cancer
}

\author{
Christoph Mundhenke Christian Schem Walter Jonat \\ University of Kiel, OB/GYN and Breast Center, Kiel, Germany
}

Key Words

Early breast cancer - Aromatase inhibitors - Letrozole . Anastrozole $\cdot$ Exemestane $\cdot$ Tamoxifen

\begin{abstract}
Five years of adjuvant tamoxifen treatment has been the gold standard for women with early hormone-responsive breast cancer. Results from two large phase III, adjuvant studies have indicated that the third-generation aromatase inhibitors (Als) letrozole and anastrozole offer greater protection against recurrence than tamoxifen in upfront substitution strategies in the first 5 years. Similarly, changeover to an $\mathrm{Al}$ (exemestane or anastrozole) after 2-3 years of tamoxifen has been more efficient to prevent recurrence than 5 years of tamoxifen. Most early breast cancer recurrences occur 5 or more years after surgery. Letrozole has been shown to offer greater protection against recurrence than placebo in the 5 years after a standard course of tamoxifen. The optimal adjuvant use (duration and sequencing) of Als requires further investigation. Safety implications of treatment with these Als for 5 years or more are closely monitored. The anticipated effects of estrogen deprivation on bone health may be treatable with bisphosphonates. Effects on the cardiovascular system, and other estrogen-sensitive systems such as the central nervous system, are currently examined. The Als letrozole, anastrozole, and exemestane have recently replaced tamoxifen as the recommended adjuvant endocrine therapy, on the basis of greater efficacy and better tolerability.
\end{abstract}

\author{
Schlüsselwörter \\ Früher Brustkrebs - Aromatasehemmer - Letrozol . \\ Anastrozol - Exemestan - Tamoxifen
}

\section{Zusammenfassung}

Fünf Jahre einer adjuvanten Tamoxifentherapie waren lange der therapeutische Goldstandard für Frauen mit frühem, hormonabhängigem Brustkrebs. Die Ergebnisse zweier großer Phase-III-Studien zeigten, dass die Aromataseinhibitoren (Als) der dritten Generation, Letrozol und Anastrozol, einen größeren Schutz vor Rezidiven bieten, wenn Tamoxifen durch die "Up-Front»-Strategie über 5 Jahre durch die Als ersetzt wird. Auch der Wechsel auf einen Al (Exemestan oder Anastrozol) nach 2-3 Jahren Tamoxifen war effizienter zur Rezidivvermeidung als eine 5-jährige Tamoxifentherapie. Die meisten Rezidive treten 5 oder mehr Jahre nach der Primärdiagnose auf. Letrozol bietet einen zusätzlichen Schutz vor Rezidiven, wenn es nach einer 5-jährigen Tamoxifentherapie für weitere 5 Jahre gegeben wird. Die optimale Anwendung (insbesondere Dauer und Sequenz) der Al-Therapie bedarf weiterer Untersuchungen. Die Sicherheit einer Al-Therapie für 5 Jahre oder länger muss weiterhin eng überwacht werden. Die erwarteten Einflüsse des Östrogenentzugs auf die Knochengesundheit könnten mit Bisphosphonaten behandelt werden. Effekte auf das kardiovaskuläre System und andere östrogenabhängige Systeme wie das Zentrale Nervensystem werden momentan untersucht. Die Als Letrozol, Anastrozol und Exemestan haben durch ihre größere Effektivität und Tolerabilität zunehmend Tamoxifen als die empfohlene adjuvante endokrine Therapie des Mammakarzinoms ersetzt.

\begin{tabular}{ll}
\hline KARGER & @ 2008 S. Karger GmbH, Freiburg \\
Fax +497614520714 & Accessible online at: \\
$\begin{array}{l}\text { Information@Karger.de } \\
\text { www.karger.com }\end{array}$ & www.karger.com/brc
\end{tabular}




\section{Introduction}

Tamoxifen has been the gold standard for endocrine adjuvant therapy in postmenopausal women with hormone receptorpositive $(\mathrm{HR}+)$ breast cancer for more than 30 years. In recent years, tamoxifen has been challenged by the third-generation aromatase inhibitors (AIs). Post-operative administration of tamoxifen for 5 years in women with HR+ early breast cancer reduces the risk of recurrence, including cancers in the contralateral breast, by $47 \%$, and the risk of death by $26 \%$ [1]. Continued tamoxifen therapy was associated with increased incidences of thromboembolic events and endometrial cancer, altering the risk-benefit balance in favor of no further treatment. Based on these results, the National Cancer Institute (NCI) guidelines recommend that adjuvant tamoxifen should be limited to 5 years [2]. Women who remain disease free after 5 years of tamoxifen therapy are at continued risk of breast cancer recurrence. The annual rates of recurrence beyond 5 years are approximately 2 and $4 \%$ in patients with nodenegative $(\mathrm{N}-)$ and node-positive $(\mathrm{N}+)$ disease [3]. Over half of the recurrences and deaths occur more than 5 years after surgery. Late recurrences occur more often in patients with estrogen-responsive tumors. This population could benefit from further endocrine therapy. The third-generation AIs (letrozole, anastrozole and exemestane) are highly selective and potent inhibitors of aromatase and well tolerated in the clinical setting. Letrozole and anastrozole are non-steroidal agents that reversibly block the activity of the enzyme. Exemestane is a steroidal AI that inhibits aromatase activity irreversibly [4]. Following the success of AI in advanced breast cancer therapy, their efficacy at other stages of disease has been studied. Neoadjuvant therapy is given to shrink and downstage a tumor prior to surgery and to increase the proportion of patients eligible for breast-conserving surgery (BCS). Letrozole proved superior to tamoxifen in patients with large, $\mathrm{HR}+\mathrm{tu}-$ mors requiring mastectomy, achieving a greater overall response rate $(\mathrm{ORR})(\mathrm{p}<0.001)$ and enabling more patients to undergo BCS than tamoxifen ( $45 \%$ vs. $35 \%$; $p=0.022$ ) [5-7]. Anastrozole also demonstrated superior efficacy to tamoxifen, allowing $45.7 \%$ of women requiring mastectomy to undergo BCS, compared with $22.2 \%(p=0.03)$ after tamoxifen: There was, however, no difference in ORR between the two treatments. Recently, several clinical trials have assessed whether incorporating AIs into adjuvant therapy could improve protection against recurrence of early breast cancer. Two strategies have been used to determine the best regimen during the first 5 years after surgery: substitution of tamoxifen with an AI, and sequential treatment with tamoxifen and an AI. The ability of AIs to alter disease outcome beyond 5 years has also been investigated.

\section{Adjuvant Therapy for Early Breast Cancer}

\section{Substitution Treatment Strategies}

The Arimidex, Tamoxifen Alone or in Combination (ATAC) and the Breast International Group (BIG) 1-98 [8] trials compare an AI (anastrozole and letrozole) with standard tamoxifen therapy. Important differences between these trials were: Hormone receptor positivity was a prerequisite for inclusion in BIG 1-98 whereas patients with hormone receptor-unknown disease were also included in ATAC. The definition of the primary endpoint, disease-free survival (DFS) (based on time from randomization to an event), also differed between the trials. The Tamoxifen and Exemestane Adjuvant Multicenter (TEAM) study was started in 2001 to compare adjuvant therapy with exemestane or tamoxifen for 5 years. In light of the Intergroup Exemestane Study (IES) results - comparing tamoxifen with a tamoxifen/exemestane sequence (see below) - TEAM was amended to include a switch from tamoxifen to exemestane after 2-3 years [9-11].

Both the ATAC and BIG 1-98 trial have reported superior efficacy for upfront anastrozole or letrozole compared with 5 years of tamoxifen in postmenopausal women with HR+ early breast cancer. The ATAC trial involved 9366 women with invasive, operable breast cancer who had completed primary therapy and were eligible for adjuvant endocrine treatment. DFS was significantly improved in the anastrozole arm $(\mathrm{p}=0.003)$, with a $15 \%$ relative risk reduction and increased time to recurrence $(\mathrm{p}=0.0001)$ after a median follow-up of 100 months. There was no difference in overall survival (OS) between the two treatment arms (hazard ratio $(\mathrm{HR})=0.97$, $\mathrm{p}=0.7)$. The absolute risk reduction for patients with confirmed HR+ tumors was cumulative over the treatment period and beyond. Anastrozole significantly reduced the risk of distant metastases $(16 \%$ reduction, $p=0.022)$ in the intention-totreat (ITT) population. Anastrozole also reduced the incidence of contralateral breast cancer by $40 \%(\mathrm{p}=0.004)$ (ITT). There is a better long-term efficacy of anastrozole compared with tamoxifen. Also evidence is provided of a larger carryover effect after 5 years of anastrozole compared with tamoxifen [12].

In the BIG 1-98 study, patients $(\mathrm{n}=8028)$ were randomized to one of four treatment arms at the onset of adjuvant therapy: tamoxifen 5 years, letrozole 5 years, tamoxifen 2 years followed by letrozole 3 years, or letrozole 2 years followed by tamoxifen 3 years. The primary core analysis of BIG 1-98 compared first-line tamoxifen and letrozole. At a median followup of 51 months, letrozole significantly improved DFS compared to tamoxifen, achieving an $18 \%$ relative risk reduction $(\mathrm{p}=0.007)$ and a $2.9 \%$ absolute risk reduction. Time to recurrence was increased by $22 \%(p=0.004)$, and risk of recurrence at distant sites, a well-recognized predictor of breast cancer-related death, was reduced by $19 \%(\mathrm{p}=0.03)$. Trends for fewer 
deaths overall and more deaths without recurrence were seen in patients receiving letrozole $(p=0.35$ and $p=0.25$, respectively). A significant improvement in OS in patients receiving letrozole has not yet been shown $[13,14]$.

\section{Sequential Treatment Strategies}

Five years of continuous first-line tamoxifen therapy has been compared with sequential treatment with 2-3 years of tamoxifen followed by exemestane in the IES trial [15-17], or 2-3 years of tamoxifen followed by anastrozole in the Austrian Breast and Colorectal Cancer Study Group (ABCSG)-8/ Arimidex-Nolvadex (ARNO) and Italian tamoxifen anastrozole (ITA) trials [18-20]. It should be noted that the primary endpoint was DFS in IES, but event-free survival (EFS) in ABCSG-8/ARNO, and disease recurrence in ITA. Sequential treatment with tamoxifen for 2 years followed by letrozole for 3 years, and vice versa, is being investigated in the BIG 1-98 trial [8]. IES, ABCSG/ARNO and ITA reported a substantial risk reduction in patients who crossed over from tamoxifen to an AI after 2-3 years (2 years in ABCSG/ARNO), compared with continued tamoxifen for up to 5 years adjuvant therapy [15-20].

A first mature analysis of the IES trial, with a median followup of 55 months, reported increased DFS (24\% relative risk reduction; $\mathrm{p}=0.0001$ ) corresponding to an absolute benefit of $3.3 \%$, a reduced incidence of contralateral breast cancer $(54 \%$ risk reduction; $p=0.04)$, and improved distant DFS $(p=0.03)$ with sequential therapy. OS, excluding all HR- patients, attained borderline significance (HR 0.83, p = 0.05) [17]. In ABCSG/ARNO, changeover to anastrozole resulted in a significant $(34 \%)$ reduction in the risk of disease recurrence ( $\mathrm{p}=0.049)$, and a $47 \%$ improved OS $(\mathrm{p}=0.045)$ compared with continuing on tamoxifen [21].

Similar results were reported in the ITA trial: Switching to anastrozole improved EFS ( $p=0.0002)$, DFS $(p=0.001)$ and local recurrence-free survival $(\mathrm{p}=0.03)$ compared with continuing tamoxifen for the entire 5-year period [20]. No differences in the risk of distant metastases were reported between study arms in this trial. However, it should be noted that ITA was a small trial $(n=448)$ with a short median follow-up. Data are not yet available from the sequential treatment arms of the BIG 1-98 trial. Rates of relapse and death in patients receiving adjuvant tamoxifen are highest during the first 2 years after surgery [3, 22, 23], which suggests that initial use of an AI may provide the greatest benefit to patients, particularly those at high risk of relapse. BIG 1-98 is the only sequential strategy trial in which randomization was performed at the onset of adjuvant therapy. IES and ITA included only patients who were disease free after 2-3 years of tamoxifen. High-risk patients who had experienced early relapse were excluded from these trials. In the ABCSG/ARNO trials, the time point for the start of the analysis was 2 years after the start of tamoxifen because the two trials had used different randomization procedures. With randomization of all treatment arms after surgery, BIG 1-98 will directly compare substitution and sequential strategies, as well as treatments within strategies, which will help to elucidate the optimal adjuvant timing and sequencing of $\mathrm{AI}$ and tamoxifen. Data from ATAC and BIG 1-98 demonstrate superior clinical efficacy of first-line AI over tamoxifen in the ITT population, which includes patients with high-risk disease. Current results indicate that AIs are an important treatment option for the adjuvant therapy of early breast cancer. However, the optimum treatment strategy has yet to be determined.

\section{Subgroup Analyses}

Subgroup analyses have suggested that hormone receptor status, prior chemotherapy, and nodal involvement may be important factors when considering adjuvant treatment options. A highly significant DFS benefit with letrozole was reported in BIG 1-98 in patients who had received prior chemotherapy $(\mathrm{HR}=0.74)$ or had $\mathrm{N}+$ disease $(\mathrm{HR}=0.77)$. In contrast, subgroup analysis in the ATAC trial revealed no benefit in patients who had received chemotherapy $(\mathrm{HR}=0.98)$ or $\mathrm{had} \geq 4$ positive nodes $(\mathrm{HR}=0.95)$ [24]. In the $\mathrm{ABCSG} / \mathrm{ARNO}$ and IES trials, switching to an AI was shown to be beneficial, irrespective of nodal status [15-20]. All patients enrolled in the ITA trial had N+ disease, and no efficacy differences were reported between patient subgroups based on prior adjuvant chemotherapy [20]. It is difficult to separate benefits in patients with $\mathrm{N}+$ disease from those in patients after chemotherapy, as these groups generally overlap. However, prior chemotherapy was an exclusion criterion in the ABCSG/ ARNO trial. In BIG 1-98, letrozole conferred a benefit in DFS in patients with estrogen receptor-positive $(\mathrm{ER}+)$ tumors, irrespective of progesterone receptor (PgR) status [8]. In contrast, retrospective analysis of data from the ATAC trial suggests that the benefit achieved with AIs may be most pronounced in patients with $\mathrm{ER}+/ \mathrm{PgR}$ - tumors [25]. Sequential tamoxifen/anastrozole therapy may also be more beneficial in patients with $\mathrm{ER}+/ \mathrm{PgR}$ - tumors than in those with $\mathrm{ER}+/ \mathrm{PgR}+$ tumors. Switching to anastrozole after 2-3 years of tamoxifen compared with continued tamoxifen reduced the risk of recurrence by $34 \%$ (HR 0.66, 95\% confidence interval (CI) $0.46-0.93, \mathrm{p}=0.0171$ ) and 58\% (HR 0.42, 95\% CI 0.19-0.92, $\mathrm{p}=0.0295)$ in $\mathrm{ER}+/ \mathrm{PgR}+$ and $\mathrm{ER}+/ \mathrm{PgR}$ - disease, compared with tamoxifen for 5 years [18-20]. A significant benefit in $\mathrm{ER}+/ \mathrm{PgR}$ - disease was not demonstrated. Sequential tamoxifen/exemestane therapy was equally effective in $\mathrm{ER}+/ \mathrm{PgR}+$ and $\mathrm{ER}+/ \mathrm{PgR}$ - tumors. Switching to exemestane after 2-3 years of tamoxifen reduced the risk of recurrence by $34 \%$ (HR 0.66, 95\% CI 0.51-0.87) and 42\% (HR 0.66, 95\% CI $0.38-0.90)$ in $\mathrm{ER}+/ \mathrm{PgR}+$ and $\mathrm{ER}+/ \mathrm{PgR}$ - disease [15-17]. The relevance of HER2/neu status in adjuvant AI treatment has 
yet to be determined. Letrozole is the only AI that has demonstrated greater efficacy than tamoxifen in patients with $\mathrm{N}+$ disease and/or those who have received chemotherapy, when given as upfront therapy [8]. Similarly, sequential therapy with exemestane after 2-3 years of tamoxifen provided a greater benefit in patients with $\geq 4$ involved nodes than in patients with 1-3 involved nodes or $\mathrm{N}-$ disease [15-17], suggesting that certain patients may benefit from treatment with one particular AI. However, such observations should be confirmed in randomized clinical trials. Comparison of data across trials is controversial, but may be useful for clinical decisions. The use of different inclusion criteria and endpoints among trials indicates that caution must be employed when drawing conclusions from such analyses. To date, no data is available of adjuvant trials directly comparing different AIs in clinical trials.

\section{Tolerability of Als in Adjuvant Therapy}

The acceptance of breast cancer treatment depends on balancing the beneficial effects on women's health with the adverse events (AE) associated with the agent used. Available data suggest that the third-generation AIs have comparable tolerability to tamoxifen. Most relevant trials have had a relatively short follow-up, and the long-term toxicities of AIs have yet to be determined. AE associated with tamoxifen may be related to its estrogenic (increased risk of thromboembolism and invasive endometrial cancer) or antiestrogenic (including hot flushes and genitourinary symptoms) effects [26]. AIs are associated with reduced incidences of gynecological and thromboembolic events and fewer cases of endometrial cancer than tamoxifen. AI therapy has been associated with musculoskeletal disorders. Arthralgia and osteoporotic fractures $(\mathrm{p}<$ 0.0001 ) were more common in patients receiving anastrozole than those receiving tamoxifen in the ATAC trial [12,23], and letrozole was associated with a $12 \%$ increase in the incidence of fractures compared with tamoxifen in the BIG 1-98 study. Results from studies of sequential therapies also suggest that AIs are associated with bone loss. More fractures occurred in patients who switched over to anastrozole than in those remaining on tamoxifen ( 34 vs. $16, \mathrm{p}=0.015$ ) in the ABCSG/ ARNO study [18-20]. In the IES trial, exemestane significantly $(\mathrm{p}<0.0001)$ reduced bone mineral density (BMD) compared with tamoxifen [15-17], and trends for increased incidences of newly diagnosed osteoporosis and fractures were reported in patients receiving sequential treatment with tamoxifen and exemestane. Tamoxifen protects the skeleton from postmenopausal bone loss [27], and this may exaggerate the effect of AIs on BMD in studies where tamoxifen is the comparator. It has been suggested that prior exposure to tamoxifen in sequential treatment regimens may protect against AIinduced bone loss [28-36]. However, clinical studies [15-17, 33 ] suggest that switching from tamoxifen to exemestane results in significant bone loss. Investigations are underway to determine how AI-induced bone loss can be prevented. Oral bisphosphonates can effectively treat and prevent postmenopausal osteoporosis outside the field of cancer therapy [37-42]. ATAC patients actively receiving anastrozole over tamoxifen had a higher annual fracture rate $(2.93 \%$ vs. $1.90 \%$, respectively; incidence rate ratio: $1.55 ; \mathrm{p}<0.0001)$, but no difference was observed in those rates after endocrine therapy was complete $(1.56 \%$ vs. $1.51 \%$, respectively; incidence rate ratio: $1.03 ; \mathrm{p}=0.79)$ [12].

The American Society of Clinical Oncology (ASCO) guidelines state that all patients receiving AI adjuvant therapy are at an increased risk of bone loss and that BMD should be monitored annually, with bisphosphonate therapy being initiated when bone loss is evident (i.e. T-score below -2.5 standard deviations) [41, 42].

Prevention of cancer treatment-induced bone loss (CTIBL) by zoledronic acid in patients receiving letrozole adjuvant therapy is currently being assessed in the Zometa-Femara Adjuvant Synergy Trials (Z-FAST/ZO-FAST): Zoledronic acid is given either at the onset of adjuvant therapy or delayed until bone loss becomes apparent [43-45]. Interim analysis at 6 months indicated that upfront zoledronic acid achieves a $3.33 \%$ improvement in bone mass, with a good safety profile [46]. These preliminary data demonstrate that zoledronic acid can protect against AI-induced bone loss. Further studies will elucidate the long-term effects of AI on bone and the importance of bisphosphonates in preventing AI-induced bone loss. Tamoxifen reduces total serum cholesterol but increases highdensity lipoprotein (HDL)-cholesterol, giving an overall advantage to the patient [47]. AIs can adversely affect lipid metabolism. The BIG 1-98 study reported a greater than twofold increase in the incidence of hypercholesterolemia with letrozole compared with tamoxifen ( $43.6 \%$ vs. $19.2 \%$, respectively): Over $80 \%$ of these incidents were grade 1 and did not require treatment. These data were based on single, non-fasting measurements of blood cholesterol, and any single event at any time during the study resulted in a positive report. Therefore, valid interpretation of these data is difficult. Furthermore, short-term (3-6 months) treatment with letrozole did not significantly affect serum low-density lipoprotein (LDL)-, HDLor total cholesterol in postmenopausal women without breast disease $[48,49]$. Also long-term analysis of letrozole in the extended adjuvant setting did not show an adverse effect on lipid metabolism compared with placebo (see below) [50]. Exemestane therapy for 2 years was associated with a modest but significant drop in HDL-cholesterol compared with placebo, but no significant effect on other lipid parameters [51]. A substudy of the TEAM trial reported no differences in total cholesterol or HDL levels between patients receiving first-line exemestane or tamoxifen therapy; however, a trend towards increased LDL levels was seen in the exemestane arm [52,53]. Data regarding lipid profiles were not systematically collected in the ATAC trial, but cholesterol levels were reported to be 2.6-fold higher in patients receiving anastrozole than in those 
taking tamoxifen (Anastrozole Product Monograph). Switching to anastrozole after 2-3 years of tamoxifen was also associated with an increased incidence of lipid metabolism disorders $(4.0 \%$ vs. $9.3 \%, p=0.04)$ in the ITA trial [20]. Effects on lipid metabolism have not been reported for ABCSG/ARNO. Further analyses using standardized measurements are required to determine the effects of AIs on lipid metabolism. Tamoxifen therapy is associated with an increased incidence of thromboembolic events [54-57]. Significantly fewer thromboembolic events were reported with AIs in the ATAC $(\mathrm{p}=0.0004)$, BIG 1-98 ( $\mathrm{p}<0.0001)$, IES $(\mathrm{p}=0.003)$ and ABCSG/ARNO ( $p=0.034)$ trials. Effects of AIs on the cardiovascular system require further investigation. The overall reported incidence of grade 3-5 cardiovascular events in BIG 1-98 was similar between the two reported treatment groups: Fewer patients receiving letrozole experienced grade 3-5 venous thromboembolic events $(0.8 \%$ vs. $2.1 \%$ for letrozole and tamoxifen), but more experienced grade 3-5 cardiac events ( $2.1 \%$ vs. $1.1 \%$ for letrozole and tamoxifen). However, the numbers were small in both groups. A non-significant increase $(\mathrm{p}=0.28)$ in the incidence of cardiovascular disease was also reported in patients switching to exemestane in the IES trial, including a 2.5 -fold increase in the number of myocardial infarctions. The ATAC study did not report cardiovascular events in detail, but a non-significant increase in ischemic cardiovascular disease was associated with anastrozole therapy. Data on cardiovascular disease were not reported in detail in the ABCSG/ARNO trial, but there was no difference in the incidence of myocardial infarction between the two study arms $(<1 \%$ in both arms). The risk of death from cardiovascular disease increases with age (Framingham Heart Study 2005), underlining the need for an age-matched population control to aid interpretation of these studies.

\section{The Extended Adjuvant Setting}

To investigate the efficacy of AIs in the extended adjuvant setting, the MA.17 trial was initiated to address the ongoing risk of late breast cancer recurrences in patients who remain disease free after 5 years of tamoxifen: More than half of breast cancer recurrences and deaths occur in women who have completed 5 years of tamoxifen $[1,32]$. The risk is higher in patients with ER+ tumors than in those with ER- tumors, despite the latter being considered the more aggressive disease [3]. AIs have the potential to alter the course of the disease in this period. In the MA.17 trial, patients with primary breast cancer were randomized to receive letrozole or placebo for 5 years, $0-3$ months after finishing approximately 5 years of tamoxifen therapy. At the first interim analysis, letrozole was found to significantly improve the primary endpoint, DFS, compared with placebo, with the effect being cumulative with increasing time on therapy [32]. The trial was therefore unblinded and patients receiving placebo were allowed to cross over to letrozole. At a median follow-up of 2.4 years, letrozole significantly improved DFS ( $\mathrm{p}=0.00008, \mathrm{HR}=0.57$ ), equating to a $43 \%$ relative reduction in risk of relapse compared with placebo. Letrozole reduced the risk of events by 53 and $40 \%$ for $\mathrm{N}-$ and $\mathrm{N}+$ disease, respectively, indicating an absolute improvement in 3-year DFS of 3 and 7\%, respectively. The final analysis was published in 2005 after a median follow-up of 30 months and reported a significant improvement in DFS with letrozole, reducing the relative risk of recurrence by $42 \%$ $(\mathrm{p}<0.001)$ and the absolute risk of recurrence at 4 years by $4.6 \%$ [31]. Letrozole also improved distant DFS, achieving a $40 \%$ reduction in the risk of recurrence $(p=0.002)$. At the final analysis, 247 DFS events and 113 deaths had occurred and 1115 patients remained disease free 40 months after randomization. OS was not significantly reduced by letrozole for the whole study population, but pre-planned subgroup analysis revealed a significant reduction in mortality in patients with $\mathrm{N}+$ disease (39\% reduction; $\mathrm{p}=0.04$ ) [31]. For the primary endpoint, DFS, HR decreased in favor of letrozole over the first 48 months of treatment from 0.52 (95\% CI 0.40-0.64) at 12 months to 0.19 (95\% CI $0.04-0.34)$ at 48 months [58]. Similar results have been reported in preliminary analysis of the ABCSG-6a open-label trial of extended adjuvant therapy with anastrozole for 3 years after completion of 5 years of adjuvant therapy with tamoxifen \pm aminoglutethimide [19]. In this study, 856 postmenopausal women who had completed either 5 years of tamoxifen or 2 years of tamoxifen plus aminoglutethimide therapy followed by tamoxifen for 3 years were randomized to either anastrozole or no further treatment for a further 3 years. With a median follow-up of 5 years, fewer patients on anastrozole experienced disease recurrence than patients who received no treatment (HR 0.64, $\mathrm{p}=0.047$ ). Treatment with anastrozole did not improve OS.

Extended adjuvant therapy with letrozole was generally well tolerated. AEs were similar to those reported in the early adjuvant setting, the majority being grade 1 or 2 . The number of discontinuations due to toxicity was low: $4.9 \%$ of women on letrozole versus $3.6 \%$ on placebo $(\mathrm{p}=0.019)$. Hot flushes $(\mathrm{p}<0.003)$, anorexia $(\mathrm{p}=0.039)$, arthralgia $(\mathrm{p}<0.001)$, myalgia $(\mathrm{p}=0.004)$ and alopecia $(\mathrm{p}=0.01)$ were more common in patients receiving letrozole than in those receiving placebo; the incidence of vaginal bleeding was lower with letrozole than with placebo $(\mathrm{p}=0.005)$ [31]. The incidence of self-diagnosed new osteoporosis was significantly higher in the letrozole group than in the placebo group (8.1 and 6.0\%, $\mathrm{p}=0.003$ ), and slightly more women receiving letrozole experienced at least one fracture (5.3\% compared with $4.6 \%$, $\mathrm{p}=0.24)$. Letrozole did not significantly increase cardiovascular disease. No adverse effects of letrozole on lipid metabolism were reported in a substudy of non-hyperlipidemic patients treated for up to 36 months (MA.17L) [50]. In contrast to the early adjuvant AI trials, lipids were measured in the fasting state in the MA.17 study, which may account for the reported differences. Furthermore, in MA.17, the comparator 
was placebo, not tamoxifen, which may have beneficial effects on lipid metabolism [47] that would tend to bias the results against AI treatment; so MA.17 may reflect more accurately the effects of letrozole on lipid metabolism. Differences seen between studies comparing an AI with tamoxifen or with placebo may reflect the protective effects of tamoxifen on organs other than the breast. Similar considerations are also important with respect to the effects of AI on the cardiovascular system. The effect of letrozole on bone was investigated in detail in the MA.17B substudy. The rate of newly diagnosed osteoporosis was monitored using dual-energy X-ray absorptiometry (DEXA) in both treatment arms $(3.3 \%$ vs. $0 \%$ for letrozole and placebo) [59]. Changes in BMD were more pronounced in the spine than in the hip, suggesting that the lumbar spine may be the best site for monitoring bone density in patients receiving long-term AI. The effect of prolonging letrozole treatment beyond 5 years is currently being addressed in the MA.17R rerandomization study, in which patients who remain disease free after completing 5 years of letrozole extended adjuvant therapy are randomized to letrozole or placebo for a further 5 years. This study will provide further data on safety issues associated with long-term use of letrozole. Toxicity data have not been reported for anastrozole extended adjuvant therapy.

\section{Overall Conclusions}

AIs are important agents in the adjuvant treatment of HR+ early breast cancer [60]. In randomized trials, AIs have proved to be superior to tamoxifen with regard to protection against recurrence and improvement in DFS when given upfront, as a substitute for tamoxifen, or in a sequential strategy after 2-3 years of tamoxifen treatment. There are currently no data directly comparing substitution and sequential strategies, so the question of the optimal AI treatment strategy remains open, but, at present, it can be stated that use of an AI as adjuvant therapy offers more protection against recurrence than single tamoxifen. Substitution studies have indicated that first-line AIs are more effective than tamoxifen and, taking into consideration the high risk of relapse during the first 2 years of tamoxifen treatment $[3,22]$, it could be argued that this strategy may provide the greatest benefit to patients. However, sequential strategies using tamoxifen followed by an AI have also proved more effective than treatment with tamoxifen for 5 years, and only direct comparative data will provide the answer as to which of these treatment strategies provides most benefit to women with early HR+ breast cancer. BIG 1-98 is the only trial that will compare substitution and sequential strategies, and the only trial in which the optimal sequence of an AI and tamoxifen is explored. In theory, tamoxifen therapy prior to an AI may be advantageous, particularly with respect to protection against the effects of AIs on bone and lipid metabolism, but data from IES do not support this suggestion as changeover to exemestane was associated with higher rates of cardiovascular disease and bone loss compared with continued tamoxifen therapy. The optimum duration of adjuvant therapy with AIs is also unknown. Currently, early adjuvant therapy is limited to 5 years because of the deleterious effects of more than 5 years of tamoxifen, but the 5-year barrier may not apply to AIs. Evidence from the MA.17 study indicates that extended adjuvant therapy with letrozole is highly effective and can alter disease outcome beyond 5 years after surgery. Data from MA.17R will help to give further detailed information on optimal AI duration. On an annual basis, approximately $1-2 \%$ of women on the placebo arm of MA.17 developed a distant recurrence during follow-up. It is important to identify patients who are at greatest risk of a distant recurrence so that these women can receive extended endocrine therapy, while perhaps sparing those women whose risk may be extremely low.

It is apparent that further studies are required to define optimal treatments using sequential and extended regimens. The question of which AI should be used also remains open. Whether pharmacological differences between AIs are clinically relevant is currently unknown, but tentative conclusions can be reached. Comparison of data across different trials suggests that letrozole therapy may have advantages in patients with $\mathrm{N}+$ disease and in patients who have received prior chemotherapy. Improved patient stratification and gene profiling studies will help to tailor therapy to the individual's needs. Monitoring and management of predictable AEs associated with AI treatment, particularly bone loss, is essential and is being addressed in ongoing trials. Standardized monitoring techniques are necessary to determine the effects of AI on lipid metabolism and the cardiovascular system. The ability of prior tamoxifen therapy to protect against these AEs must be clarified. Cost considerations are particularly important in countries where generic drugs are many times cheaper than patented brands, and benefits such as fewer recurrences, and differences in toxicity profiles leading to lower secondary costs and improved quality of life, are difficult to quantify. Health economic studies have shown that adjuvant letrozole and anastrozole therapy and extended adjuvant letrozole therapy are cost-effective treatments in postmenopausal patients with HR+ early breast cancer [41, 61-63]. It can be concluded that AIs represent an important advance in the treatment of early breast cancer, and that 5 years of treatment with tamoxifen can no longer be considered an acceptable standard of care for postmenopausal women with HR+ early breast cancer. Incorporation of AIs into early adjuvant therapies, and AIs in the extended adjuvant period, has the potential to alter the course of early breast cancer for at least 10 years after surgery, improving outcomes for women with this common disease. Ongoing and future studies will help to determine how to balance the beneficial and detrimental effects of AIs on women's health and maximize the clinical impact of these agents in the treatment of breast cancer. 


\section{References}

1 Early Breast Cancer Trialists' Collaborative Group: Effects of chemotherapy and hormonal therapy for early breast cancer on recurrence and 15 -year survival: an overview of the randomized trials. Lancet 2005;365:1687-1717.

2 Swain SM: Tamoxifen: the long and short of it. J Natl Cancer Inst 1996;88:1510-1512.

3 Saphner T, Tormey DC, Gray R: Annual hazard rates of recurrence for breast cancer after primary therapy. J Clin Oncol 1996;14:2738-2746.

4 Campos SM: Aromatase inhibitors for breast cancer in postmenopausal women. Oncologist 2004;9: 126-136.

$\checkmark 5$ Eiermann W, Paepke S, Appfelstaedt J, LlombartCussac A, Eremin J, Vinholes J, Mauriac L, Ellis M, Lassus M, Chaudri-Ross HA, Dugan M, Borgs M: Preoperative treatment of postmenopausal breast cancer patients with letrozole: a randomized double-blind multicenter study. Ann Oncol 2001;12: 1527-1532.

6 Smith IE: Letrozole versus tamoxifen in the treatment of advanced breast cancer and as neoadjuvan therapy. J Steroid Biochem Mol Biol 2003;86: 289-293.

7 Smith I, Dowsett M; IMPACT Trialists' Group: Comparison of anastrozole vs tamoxifen alone and in combination as neoadjuvant treatment of estrogen receptor-positive $(\mathrm{ER}+)$ operable breast cancer in postmenopausal women: the IMPACT trial (abstract). Breast Cancer Res Treat 2003;82:S7.

8 Breast International Group (BIG) 1-98 Collaborative Group, Thürlimann B, Keshaviah A, Coates AS, Mouridsen H, Mauriac L, Forbes JF, Paridaens R, Castiglione-Gertsch M, Gelber RD, Rabaglio M, Smith I, Wardley A, Price KN, Goldhirsch A: A comparison of letrozole and tamoxifen in postmenopausal women with early breast cancer. N Engl J Med. 2005;353:2747-2757.

$\checkmark 9$ Mouridsen H, Gershanovich M, Sun Y, Perez-Carrion R, Boni C, Monnier A, Apffelstaedt J, Smith R Sleeboom HP, Janicke F, Pluzanska A, Dank M, Becquart D, Bapsy PP, Salminen E, Snyder R, Lassus M, Verbeek JA, Staffler B, Chaudri-Ross HA, Dugan M: Superior efficacy of letrozole versus tamoxifen as first-line therapy for postmenopausal women with advanced breast cancer: results of a phase III study of the International Letrozole Breast Cancer Group. J Clin Oncol 2001;19:25962606. Erratum in: J Clin Oncol 2001;19:3302.

10 Mouridsen H, Gershanovich M, Sun Y, Perez-Carrion R, Boni C, Monnier A, Apffelstaedt J, Smith R, Sleeboom HP, Jaenicke F, Pluzanska A, Dank M, Becquart D, Bapsy PP, Salminen E, Snyder R, Chaudri-Ross H, Lang R, Wyld P, Bhatnagar A: Phase III study of letrozole versus tamoxifen as first-line therapy of advanced breast cancer in women: analysis of survival and update of efficacy from the International Letrozole Breast Cancer Group. J Clin Oncol 2003;21:2101-2109.

11 Mouridsen H, Sun Y, Gershanovich M, Perez-Carrion R, Becquart D, Chaudri-Ross HA, Lang R: Superiority of letrozole to tamoxifen in the first-line treatment of advanced breast cancer: evidence from metastatic subgroups and a test of functional ability. Oncologist 2004;9:489-496.

12 Forbes JF, Cuzick J, Buzdar A, Howell A, Tobias JS, Baum M, on behalf of the Arimidex, Tamoxifen Alone or in Combination (ATAC) Trialists' Group: Effect of anastrozole and tamoxifen as adjuvant treatment for early-stage breast cancer: 100-month analysis of the ATAC trial. Lancet Oncol 2008;9: 45-53.
13 Coates AS, Keshaviah A, Thürlimann B, Mouridsen H, Mauriac L, Forbes JF, Paridaens R, CastiglioneGertsch M, Gelber RD, Colleoni M, Láng I, Del Mastro L, Smith I, Chirgwin J, Nogaret J-M, Pienkowski T, Wardley A, Jakobsen EH, Price KN, Goldhirsch A: Five years of letrozole compared with tamoxifen as initial adjuvant therapy for postmenopausal women with endocrine-responsive early breast cancer: update of study BIG 1-98. J Clin Oncol 2007;25:486-492.

14 Mouridsen HT, Robert NJ: The role of aromatase inhibitors as adjuvant therapy for early breast cancer in postmenopausal women. Eur J Cancer 2005;41:1678-1689.

15 Coombes RC, Hall E, Gibson LJ, Paridaens R, Jassem J, Delozier T, Jones SE, Alvarez I, Bertelli G, Ortmann O, Coates AS, Bajetta E, Dodwell D, Coleman RE, Fallowfield LJ, Mickiewicz E, Andersen J, Lonning PE, Cocconi G, Stewart A, Stuart N, Snowdon CF, Carpentieri M, Massimini G, Bliss JM; Intergroup Exemestane Study: A randomized trial of exemestane after two to three years of tamoxifen therapy in postmenopausal women with primary breast cancer. N Engl J Med 2004;350: 1081-1092. Erratum in: N Engl J Med 2004;351: 2461.

16 Coombes RC, Hall E, Snowdon CF, Bliss JM; The Intergroup Exemestane Study: A randomized trial in postmenopausal patients with early breast cancer who remain disease-free after two to three years of tamoxifen-updated survival analysis (abstract). Breast Cancer Res Treat 2004;88:S7.

17 Coombes RC, Kilburn LS, Snowdon CF, Paridaens R, Coleman RE, Jones SE, Jassem J, Van de Velde CJ, Delozier T, Alvarez I, Del Mastro L, Ortmann O, Diedrich K, Coates AS, Bajetta E, Holmberg SB, Dodwell D, Mickiewicz E, Andersen J, Lønning PE, Cocconi G, Forbes J, Castiglione M, Stuart N, Stewart A, Fallowfield LJ, Bertelli G, Hall E, Bogle RG, Carpentieri M, Colajori E, Subar M, Ireland E, Bliss JM; Intergroup Exemestane Study: Survival and safety of exemestane versus tamoxifen after 2-3 years' tamoxifen treatment (Intergroup Exemestane Study): a randomised controlled trial. Lancet 2007;369:559-570.

18 Jakesz R, Jonat W, Gnant M, Mittlboeck M, Greil R, Tausch C, Hilfrich J, Kwasny W, Menzel C, Samonigg H, Seifert M, Gademann G, Kaufmann M, Wolfgang J; ABCSG, the GABG: Switching of postmenopausal women with endocrineresponsive early breast cancer to anastrozole after 2 years' adjuvant tamoxifen: combined results of ABCSG trial 8 and ARNO 95 trial. Lancet 2005;366:455-462.

19 Jakesz R, Samonigg H, Greil R, Gnant M, Schmid M, Kwasny W, Kubista E, Mlineritsch B, Tausch C, Stierer M, on behalf of the ABCSG: Extended adjuvant treatment with anastrozole: results from the Austrian Breast and Colorectal Cancer Study Group Trial 6a (ABCSG-6a) (abstract). J Clin Oncol 2005;23:10S.

20 Boccardo F, Rubagotti A, Puntoni M, Guglielmini P, Amoroso D, Fini A, Paladini G, Mesiti M, Romeo D, Rinaldini M, Scali S, Porpiglia M, Benedetto C, Restuccia N, Buzzi F, Franchi R, Massidda B, Distante V, Amadori D, Sismondi P: Switching to anastrozole versus continued tamoxifen treatment of early breast cancer: preliminary results of the Italian tamoxifen anastrozole trial. J Clin Oncol 2005; 23:5138-5147.
1 Kaufmann M, Jonat W, Hilfrich J, Eidtmann H, Gademann G, Zuna I, von Minckwitz G: Improved overall survival in postmenopausal women with early breast cancer after anastrozole initiated after treatment with tamoxifen compared with continued tamoxifen: the ARNO 95 Study. J Clin Oncol 2007; 25:2664-2670.

22 Howell A, Cuzick J, Baum M, Buzdar A, Dowsett M, Forbes JF, Hoctin-Boes G, Houghton J, Locker GY, Tobias JS; ATAC Trialists' Group: Results of the ATAC (Arimidex, Tamoxifen, Alone or in Combination) trial after completion of 5 years' adjuvant treatment for breast cancer. Lancet 2005 ; 365:60-62.

23 Howell A: An early peak of relapse after surgery for breast cancer. Breast Cancer Res 2004;6: 255-257.

24 Baum M, Buzdar A, Cuzick J, Forbes J, Houghton J, Howell A, Sahmoud T; The ATAC (Arimidex, Tamoxifen Alone or in Combination) Trialists' Group: Anastrozole alone or in combination with tamoxifen versus tamoxifen alone for adjuvant treatment of postmenopausal women with earlystage breast cancer: results of the ATAC (Arimidex, Tamoxifen Alone or in Combination) trial efficacy and safety update analyses. Cancer 2003;98: 1802-1810.

25 Dowsett M, Cuzick J, Wale C, Howell T, Houghton J, Baum M: Retrospective analysis of time to recurrence in the ATAC trial according to hormone receptor status: an hypothesis-generating study. J Clin Oncol 2005;23:7512-7517.

26 Robinson E, Kimmick GG, Muss HB: Tamoxifen in postmenopausal women a safety perspective. Drugs Aging 1996;8:329-337.

27 Powles TJ, Hickish T, Kanis JA, Tidy A, Ashley S: Effect of tamoxifen on bone mineral density measured by dual-energy Xray absorptiometry in healthy premenopausal and postmenopausal women. J Clin Oncol 1996;14:78-84.

28 Goss PE, Ingle JN, Martino S, Robert NJ, Muss HB, Piccart MJ, Castiglione M, Tu D, Shepherd LE, Pritchard KI, Livingston RB, Davidson NE, Norton L, Perez EA, Abrams JS, Therasse P, Palmer MJ, Pater JL: A randomized trial of letrozole in postmenopausal women after five years of tamoxifen therapy for early-stage breast cancer. N Engl J Med 2003;349:1793-1802.

29 Goss PE, Qi S, Josse RG, Pritzker KP, Mendes M, Hu H, Waldman SD, Grynpas MD: The steroidal aromatase inhibitor exemestane prevents bone loss in ovariectomized rats. Bone 2004;34:384-392.

30 Goss PE, Qi S, Cheung AM, Hu H, Mendes M, Pritzker KP: Effects of the steroidal aromatase inhibitor exemestane and the nonsteroidal aromatase inhibitor letrozole on bone and lipid metabolism in ovariectomized rats. Clin Cancer Res 2004;10: $5717-5723$.

31 Goss PE, Ingle JN, Martino S, Robert NJ, Muss HB, Piccart MJ, Castiglione M, Tu D, Shepherd LE, Pritchard KI, Livingston RB, Davidson NE, Norton L, Perez EA, Abrams JS, Cameron DA, Palmer MJ, Pater JL: Randomized trial of letrozole following tamoxifen as extended adjuvant therapy in receptorpositive breast cancer: updated findings from NCIC CTG MA.17. J Natl Cancer Inst 2005;97: 1262-1271. 
\32 Goss PE, Ingle JN, Pater JL, Martino S, Robert NJ, Muss HB, Piccart MJ, Castiglione M, Shepherd LE, Pritchard KI, Livingston RB, Davidson NE, Norton L, Perez EA, Abrams JS, Cameron DA, Palmer MJ, Tu D: Late extended adjuvant treatment with letrozole improves outcome in women with early-stage breast cancer who complete 5 years of tamoxifen. $\mathrm{J}$ Clin Oncol 2008;26:1948-1955.

33 Lønning PE, Geisler J, Krag LE, Ottestad L, Bremnes Y, Hagen AI, Schlichting E, Polli A, Paolini J, Massimini G: Effect of exemestane on bone: A randomized placebo controlled study in postmenopausal women with early breast cancer at low risk (abstract). Proc ASCO 2004;23:6.

34 Kanis JA, McCloskey EV, Powles T, Paterson AH, Ashley S, Spector T: A high incidence of vertebral fracture in women with breast cancer. Br J Cancer 1999;79:1179-1181.

35 Theriault RL, Hortobagyi GN: Bone metastasis in breast cancer. Anticancer Drugs 1992;3:455-462.

36 Mincey BA, Moraghan TJ, Perez EA: Prevention and treatment of osteoporosis in women with breast cancer. Mayo Clin Proc 2000;75:821-829. Erratum in: Mayo Clin Proc 2001;76:113.

37 Pfeilschifter J, Diel IJ: Osteoporosis due to cancer treatment: pathogenesis and management. J Clin Oncol 2000;18:1570-1593.

38 Ramaswamy B, Shapiro CL: Osteopenia and osteoporosis in women with breast cancer. Semin Onco 2003;30:763-775.

39 Kessel B: Hip fracture prevention in postmenopausal women. Obstet Gynecol Surv 2004;59: 446-455.

40 Lippuner K: Medical treatment of vertebral osteoporosis. Eur Spine J 2003;12:S132-S141.

41 Hillner BE, Ingle JN, Chlebowski RT, Gralow J, Yee GC, Janjan NA, Cauley JA, Blumenstein BA, Albain KS, Lipton A, Brown S: American Society of Clinical Oncology 2003 update on the role of bisphosphonates and bone health issues in women with breast cancer. J Clin Oncol 2003;21:4042-4057. Erratum in: J Clin Oncol 2004;22:1351.

42 Hillner BE: Benefit and projected cost-effectiveness of anastrozole versus tamoxifen as initial adjuvant therapy for patients with early-stage estrogen receptor-positive breast cancer. Cancer 2004;101: 1311-1322.

43 Reid IR, Brown JP, Burckhardt P, Horowitz Z, Richardson P, Trechsel U, Widmer A, Devogelaer JP, Kaufman JM, Jaeger P, Body JJ, Brandi ML, Broell J, Di Micco R, Genazzani AR, Felsenberg D, Happ J, Hooper MJ, Ittner J, Leb G, Mallmin H, Murray T, Ortolani S, Rubinacci A, Saaf M, Samsioe G, Verbruggen L, Meunier PJ: Intravenous zoledronic acid in postmenopausal women with low bone mineral density. N Engl J Med 2002;346: 653-661.

44 Gnant M, Jakesz R, Mlineritsch B, Luschin-Ebengreuth G, Schmid M, Menzel C, Kubista E, Samonigg $\mathrm{H}$, Hausmaninger $\mathrm{H}$; the ABCSG Austrian Breast and Colorectal Cancer Study Group: Zoledronic acid effectively counteracts cancer treatment induced bone loss (CTIBL) in premenopausal breast cancer patients receiving adjuvant endocrine treatment with goserelin plus anastrozole versus goserelin plus tamoxifen - bone density subprotocol results of a randomized multicenter tria (ABCSG-12) (abstract). Breast Cancer Res Treat 2004;88:S8.
45 Gnant M, Mlineritsch B, Schippinger W, LuschinEbengreuth G, Poestlberger S, Menzel C, Jakesz R, Kubista E, Marth C, Greil R: Adjuvant ovarian suppression combined with tamoxifen or anastrozole, alone or in combination with zoledronic acid, in premenopausal women with hormone-responsive, stage I and II breast cancer: First efficacy results from ABCSG-12. J Clin Oncol 2008;26(suppl):abstr LBA4.

46 Brufsky A, Harker G, Beck T, Carroll R, Tan-Chiu E, Seidler C, Lacema L, Thomas E, Perez E: Z-FAST Study Group: Zoledronic acid (ZA) for prevention of cancer treatment-induced bone loss (CTIBL) in postmenopausal women (PMW) with early breast cancer (BCa) receiving adjuvant letrozole (Let): preliminary results of the Z-FAST trial (abstract). Breast Cancer Res Treat 2004;88:S233.

47 Morales M, Santana N, Soria A, Mosquera A, Ordovas J, Novoa J, Betancor P, Valeron PF, DiazChico B, Chirino R: Effects of tamoxifen on serum lipid and apolipoprotein levels in postmenopausal patients with breast cancer. Breast Cancer Res Treat 1996;40:265-270.

48 Harper-Wynne C, Ross G, Sacks N, Salter J, Nasiri N, Iqbal J, A'Hern R, Dowsett M: Effects of the aromatase inhibitor letrozole on normal breast epithelial cell proliferation and metabolic indices in postmenopausal women: a pilot study for breast cancer prevention. Cancer Epidemiol Biomarkers Prev 2002;11:614-621.

49 Heshmati HM, Khosla S, Robins SP, O'Fallon WM, Melton LJ 3rd, Riggs BL: Role of low levels of endogenous estrogen in regulation of bone resorption in late postmenopausal women. J Bone Miner Res 2002;17:172-178.

50 Wasan KM, Goss PE, Pritchard PH, Shepherd L, Palmer MJ, Liu S, Tu D, Ingle JN, Heath M, Deangelis D, Perez EA: The influence of letrozole on serum lipid concentrations in postmenopausal women with primary breast cancer. Ann Oncol 2005;16:707-715.

51 Krag LE, Geisler J, Lonning PE, Ottestad L, Risberg T, Hagen AI, Lien EA, Polli A, Paolini J, Massimini G: Lipid and coagulation profile in postmenopausal women with early breast cancer at low risk treated with exemestane: a randomized, placebo-controlled study (abstract). Proc ASCO 2004;23: S39.

52 Markopoulos C, Polychronis A, Farfarelos C, Zobolas V, Papadiamantis J, Bafaloukos D, Misitzis J, Michailidou A, Gogas H; Hellenic Breast Surgical Society: The effect of exemestane on the lipidemic profile of breast cancer patients: Preliminary results of the TEAM trial Greek substudy (abstract). Proc ASCO 2004;23:76.

53 Atalay G, Dirix L, Biganzoli L, Beex L, Nooij M, Cameron D, Lohrisch C, Cufer T, Lobelle JP, Mattiaci MR, Piccart M: The effect of exemestane on serum lipid profile in postmenopausal women with metastatic breast cancer: a companion study to EORTC Trial 10951, 'Randomized phase II study in first line hormonal treatment for metastatic breast cancer with exemestane or tamoxifen in postmenopausal patients'. Ann Oncol 2004;15: 211-217.
4 Fisher B, Dignam J, Bryant J, DeCillis A, Wickerham DL, Wolmark N, Costantino J, Redmond C, Fisher ER, Bowman DM, Deschenes L, Dimitrov NV, Margolese RG, Robidoux A, Shibata H, Terz J, Paterson AH, Feldman MI, Farrar W, Evans J, Lickley HL: Five versus more than five years of tamoxifen therapy for breast cancer patients with negative lymph nodes and estrogen receptor-positive tumors. J Natl Cancer Inst 1996;88:1529-1542.

55 Fisher B, Costantino JP, Wickerham DL, Redmond CK, Kavanah M, Cronin WM, Vogel V, Robidoux A, Dimitrov N, Atkins J, Daly M, Wieand S, TanChiu E, Ford L, Wolmark N: Tamoxifen for prevention of breast cancer: report of the National Surgical Adjuvant Breast and Bowel Project P-1 Study. J Natl Cancer Inst 1998;90:1371-1388.

56 Fisher B, Dignam J, Bryant J, Wolmark N: Five versus more than five years of tamoxifen for lymph node-negative breast cancer: updated findings from the National Surgical Adjuvant Breast and Bowel Project B-14 randomized trial. J Natl Cancer Inst 2001;93:684-690.

57 McDonald CC, Alexander FE, Whyte BW, Forrest AP, Stewart HJ: Cardiac and vascular morbidity in women receiving adjuvant tamoxifen for breast cancer in a randomised trial. BMJ 1995;311: 977-980.

58 Ingle J, Goss PE, Dongsheng Y; NCIC CTG MA.17: Increasing benefit of letrozole with longer duration of treatment as measured by the hazard ratio of disease recurrence over time (abstract). Eur J Cancer Suppl 2005;3:74.

59 Perez EA, Josse RG, Pritchard KI, Ingle JN, Martino S, Findlay BP, Shenkier TN, Tozer RG, Palmer MJ, Shepherd LE, Tu D, Goss PE: Effect of letrozole versus placebo on bone mineral density in women completing 5 years (yrs) of adjuvant tamoxifen: NCIC CTG MA.17B (abstract). Breast Cancer Res Treat 2004;88:S36

60 Delea TE, Karnon J, Smith RE, Brandman J, Sung JC, Goss PE: Cost-effectiveness of five years of extended adjuvant letrozole in postmenopausal women with early breast cancer who have completed five years of adjuvant tamoxifen (abstract). Breast Cancer Res Treat 2004;88:S4

61 Karnon J, Johnston SRD, Delea T, Barghout V, Thomas S, Papo NL: Letrozole is cost-effective versus tamoxifen as adjuvant therapy in postmenopausal women with early breast cancer: BIG 1-98 (abstract). Eur J Cancer Suppl 2005;3:96.

62 Jackisch C, Schneeweiss A: Adjuvant endocrine therapy in pre- and postmenopausal patients. Breast Care 2006;1:242-247.

63 Verma S, Rocchi A, Cheung S: Canadian cost-effectiveness analysis of anastrozole versus tamoxifen in early breast cancer (abstract). Breast Cancer Res Treat 2003;82:S157. 